Check for updates

Cite this: RSC Adv., 2019, 9, 9899

Received 26th November 2018 Accepted 30th January 2019

DOI: $10.1039 / c 8 r a 09732 a$

rsc.li/rsc-advances

\section{Specific capture of glycosylated graphene oxide by an asialoglycoprotein receptor: a strategic approach for liver-targeting}

Kevin R. Diaz-Galvez, (D) a Nayelli G. Teran-Saavedra, (D) a Alexel J. BurgaraEstrella, (iD ${ }^{\mathrm{b}}$ Daniel Fernandez-Quiroz, (DD ${ }^{\mathrm{b}}$ Erika Silva-Campa, (iD ${ }^{\mathrm{b}}$ Monica AcostaElias, ${ }^{b}$ Hector M. Sarabia-Sainz, (D) c Martín R. Pedroza-Montero (DD ${ }^{b}$ and Jose A. Sarabia-Sainz (D)*b

In this work, we report the evaluation of lactosylated graphene oxide (GO-AL) as a potential drug carrier targeted at an asialoglycoprotein receptor (ASGPR) from hepatic cancer cells. Structural-modification, safety evaluation, and functional analysis of GO-AL were performed. The structure and morphology of the composite were analyzed by scanning electron microscopy (SEM) and atomic force microscopy (AFM), while Raman and FTIR spectroscopy were used to track the chemical modification. For the safe application of GO-AL, an evaluation of the cytotoxic effect, hemolytic properties, and specific interactions of the glycoconjugate were also studied. SEM and AFM analysis of the GO showed graphene sheets with a layer size of $2-3 \mathrm{~nm}$, though a few of them reached $4 \mathrm{~nm}$. The Raman spectra presented characteristic peaks of graphene oxide at $1608 \mathrm{~cm}^{-1}$ and $1350 \mathrm{~cm}^{-1}$, corresponding to $G$ and $\mathrm{D}$ bands, respectively. Besides, $\mathrm{Si}-\mathrm{O}$ peaks for the APTES conjugates of GO were identified by FTIR spectroscopy. No cytotoxic or hemolytic effects were observed for GO samples, thus proving their biocompatibility. The interaction of Ricinus communis lectin confirmed that GO-AL has a biorecognition capability and an exposed galactose structure. This biorecognition capability was accompanied by the determination of the specific absorption of lactosylated GO by HepG2 cells mediated through the asialoglycoprotein receptor. The successful conjugation, hemolytic safety, and specific recognition described here for lactosylated GO indicate its promise as an efficient drugdelivery vehicle to hepatic tissue.

\section{Introduction}

Graphene oxide (GO) possesses a unique combination of physical and chemical properties with potential applications in nanoelectronics, nanosensor production, and the synthesis of bio-composites. ${ }^{1}$ These carbon-based nanomaterials are highly dispersible in water and have hydrophilic functional groups that enable chemical functionalization and a high surface area for the immobilization of molecules. ${ }^{2}$ These properties can be applied in biomedicine and clinical settings. Recently, GO obtained by the oxidation of graphite under acidic conditions, as first described by Hummers and Offeman, ${ }^{3}$ has been studied for in vitro drug deliveries and cellular imaging. ${ }^{4} \mathrm{GO}$ has also been

${ }^{a}$ Departamento de Investigación en Polímeros y Materiales, Universidad de Sonora, Hermosillo, Mexico

${ }^{b}$ Departamento de Investigación en Física, Universidad de Sonora, Hermosillo, Mexico. E-mail: jose.sarabia@unison.mx

'Departamento de Ciencias del Deporte y de la Actividad Física, Universidad de Sonora, Hermosillo, Mexico employed as a carrier for the controlled release of antitumor agents. $^{5}$

GO nanomaterials can be engineered for target-drug delivery through their surface functionalization with different biomolecules. Conjugating GO with tumor-selective molecules such as peptides, ligands, and antibodies could potentially improve the in vivo targeting of anti-cancer drugs. In this sense, the high specificity of the asialoglycoprotein receptor (ASGPR) towards some carbohydrates can be explored. ${ }^{6}$ ASGPRs are lectin receptors located on the sinusoidal membrane of hepatocytes. They bind and remove asialoglycoproteins, like "old immunoglobulins", from circulation. ASGPR is the most common target site of the liver because of the high expression of hepatocytes and hepatoma cells. ${ }^{6}$ Other benefits include ease of access from the vascular compartment and the ability to internalize large molecules through clathrin-mediated endocytosis. ${ }^{7,8}$

Various groups have reported hepatocyte-specific targeted delivery via ASGPR using simple or complex sugars as a ligand coupled with the carriers. ${ }^{9}$ Roggenbuck, Mytilinaiou et al. ${ }^{10}$ reported that saccharides containing D-galactose, $N$-acetylgalactosamine or D-glucose residues are potential ligands for the 
targeting of liver cells mediated by ASGPR recognition. Arabinogalactan, a polymer based on galactose, and pullulan, a polymer based on glucose, are among the carbohydrate ligands most widely studied for liver targeting. ${ }^{\mathbf{1 1 2} 12}$ However, lactose has shown greater affinity and specificity towards ASGPR than other ligands ${ }^{\mathbf{1 3}}$ due to the lactose structure being composed of galactose and glucose ( $\beta$-D-galactopyranosyl-(1-4)D-glucose), forming a disaccharide that complies with the key factors for the interaction with ASGPR.

This work aimed to synthesize lactose-modified graphene oxide (GO-AL) to promote a specific interaction with hepatic receptors. The nanomaterials were obtained by the oxidation of graphite, and then lactosylation was performed by thermal glycation. The obtained nanocomposite was characterized physicochemically, and its biocompatibility properties were also evaluated. The exposure of galactose for specific recognition was studied using carbohydrate-specific lectins as well as the selective HepG2 cell uptake.

\section{Experimental}

\subsection{Materials}

Graphite flakes, fluorescein-NHS, Dulbecco's modified Eagle's medium (DMEM), and fetal bovine serum (FBS) were purchased from Sigma-Aldrich (St. Louis, MO, USA). HepG2 (human liver cancer) and HeLa (human cervical carcinoma) cells were obtained from ATCC (Manassas, VA, USA). Unless specified, all other reagents and chemicals were purchased from SigmaAldrich. All the experiments were carried out using Type 2 pure water $\left(0.18 \mu \mathrm{S} \mathrm{cm}^{-1}\right)$.

\subsection{Preparation of graphene oxide}

Oxidation of graphite was carried out according to the modified Hummers method. ${ }^{3}$ Briefly, graphite powder $(0.25 \mathrm{~g})$ was suspended in sulfuric acid $\left(\mathrm{H}_{2} \mathrm{SO}_{4}, 15 \mathrm{~mL}\right)$ and was kept in an ice bath for 25 min with stirring. Subsequently, sodium nitrate $\left(\mathrm{NaNO}_{3}, 0.25 \mathrm{~g}\right)$ was added to the suspension and the mixture was stirred for $60 \mathrm{~min}$. Then, potassium permanganate $(1.2 \mathrm{~g})$ was slowly added, maintaining a temperature of $35{ }^{\circ} \mathrm{C}$ for $60 \mathrm{~min}$. Later, $50 \mathrm{~mL}$ of water was added, and then hydrogen peroxide ( $5 \mathrm{~mL}, 30 \mathrm{vol} \%$ ) was slowly added to the reaction mixture with stirring for $30 \mathrm{~min}$. In this step, an exothermic effect was produced with the mixture reaching a temperature $\sim 73{ }^{\circ} \mathrm{C}$, which was then cooled in an ice bath. Finally, the samples were washed using water and several centrifugation cycles were applied $\left(2422 \times g, 10 \mathrm{~min}\right.$ at $\left.25^{\circ} \mathrm{C}\right)$.

For the complete exfoliation of GO, the resultant suspension $(20 \mathrm{~mL})$ was sonicated in an ice bath (Q500 ultrasonic processor, 500 watts, QSONICA, 30 pulses, 35\% amplitude dial setting) for $15 \mathrm{~min}$. Then, the suspension was centrifuged $\left(2422 \times g, 10 \mathrm{~min}\right.$ at $\left.25^{\circ} \mathrm{C}\right)$, and the precipitate was dehydrated at $60{ }^{\circ} \mathrm{C}$ for 7 days.

\subsection{Graphene oxide lactosylation}

Functionalization of the GO with lactose was performed as follows: first, $50 \mathrm{mg}$ of $\mathrm{GO}$ was suspended in $30 \mathrm{~mL}$ of ethanol.
Then, (3-aminopropyl)triethoxysilane (APTES, $2.4 \mathrm{mM}$ ) was added to the solution and stirred at $40{ }^{\circ} \mathrm{C}$ for $24 \mathrm{~h}$. The resulting particles were washed two times with water $(2422 \times g$ for 10 min), then the supernatant was discarded, and the resultant pellet was resuspended in $20 \mathrm{~mL}$ of water. Once GO with $-\mathrm{NH}_{2}$ groups was obtained, lactose $(50 \mathrm{mg}$ ) was added and the solution was left at $40{ }^{\circ} \mathrm{C}$ for 3 days to promote the glycation reaction. After incubation, the suspension was washed with water and centrifuged $(2422 \times g$ for $10 \mathrm{~min})$. Next, the lactosylated GO (GO-AL) was precipitated by centrifugation and dried at $60{ }^{\circ} \mathrm{C}$ for 7 days. As a control, GO without modification and GO modified with APTES (GO-A) samples were prepared.

\subsection{Characterization of the lactosylated graphene oxide}

Raman spectra of GO, GO-A, and GO-AL samples were acquired with a Raman micro-spectrometer (Alpha300RA, WiTec, Ulm, Germany) using a frequency doubled Nd:YAG laser excitation of $532 \mathrm{~nm}$ (CW - continuous wave). The samples were prepared as follows: $10 \mathrm{mg}$ of the resultant powder was suspended in $500 \mu \mathrm{L}$ of water, and then $10 \mu \mathrm{L}$ of the suspension was placed on a silicon substrate, allowed to dry, and subsequently the Raman spectrum was obtained. The Raman measurements were carried out with $10 \mathrm{~s}$ accumulation time, $10 \mathrm{~mW}$ laser power, and a $0.68 \mu \mathrm{m}$ spot size. FTIR spectra were obtained using a FTIR Perkin-Elmer Frontier spectrometer. Approximately $5 \mathrm{mg}$ portions of the dry samples were directly dispersed into a $\mathrm{KBr}$ pellet for the FTIR measurements. Background spectra were collected using pure $\mathrm{KBr}$ pellets. The spectra were recorded at room temperature over 16 scans, using a resolution of $4 \mathrm{~cm}^{-1}$.

\subsection{Morphological characterization}

The morphology of GO and functionalized GO were characterized by scanning electron microscopy (SEM; JEOL, JSM-7800F, Akishima, Tokyo, Japan) and atomic force microscopy (Alpha300RA, WiTec, Ulm, Germany). SEM images were obtained with a magnification of $\times 10000$ using an acceleration voltage of $5.0 \mathrm{kV}$. Atomic force microscopy (AFM) images were reconstructed in the non-contact mode using a probe with a spring constant of $42 \mathrm{~N} \mathrm{~m}^{-1}$ and a resonant frequency of $285 \mathrm{kHz}$. An optical microscope was used to focus the sample on the slice, and then the area of analysis of the GO sheets was randomly selected and scanned. The shape analysis was performed from $5 \times 5 \mu \mathrm{m}$ scans for each specimen. The morphology and height profile of the GO and functionalized GO were analyzed with the software program WiTec project FOUR v4.1.

\subsection{Zeta potential}

The zeta potential of GO samples was determined by laser Doppler anemometry using a Zetasizer Nano ZS 90 instrument (Malvern Instruments Ltd., Malvern, UK). The measurements were performed at $25{ }^{\circ} \mathrm{C}$. The GO samples $\left(1 \mathrm{mg} \mathrm{mL}{ }^{-1}\right)$ were dispersed in $10 \mathrm{mM}$ phosphate buffer saline (PBS) at $\mathrm{pH}$ 7.2, saline solution, DMEM (Dulbecco modified eagles medium), or water. All the measurements were done in triplicate. 


\subsection{Enzyme-linked lectin assay (ELLA): GO-lactose confirmation}

The interaction of Ricinus communis agglutinin I (RCA) with lactosylated GO was analyzed by ELLA. Briefly, samples were adsorbed on an ELISA plate, with $50 \mathrm{mg} 100 \mu \mathrm{L}^{-1}$ (PBS with 1 vol\% of glutaraldehyde, $\mathrm{pH}$ 7.2) placed in wells and incubated for $2 \mathrm{~h}$. After extensive washes with PBS, the wells were blocked for $3 \mathrm{~h}$ with $1.5 \%$ BSA in PBS. Then, $100 \mu \mathrm{L}$ of biotin-labeled RCA ( $1 \mathrm{mg} \mathrm{mL}^{-1}$ ) was added and incubated for $2 \mathrm{~h}$. After four washes with $\mathrm{PBS}$, the plates were treated with avidin-peroxidase $(1 / 1000 \mathrm{v} / \mathrm{v}$ in $\mathrm{PBS}, \mathrm{pH} 7.5)$ for $1 \mathrm{~h}$ and the interaction was revealed using $O$-phenylenediamine. GO and GO modified only with APTES were used as the negative controls.

\subsection{In vitro biocompatibility of GO studies}

2.8.1. Hemolytic properties of GO. The hemolytic effect of GO samples was determined by the hemolysis of red blood cells (RBCs). The experiments were approved by the Ethics Committee of Sonora University, and complied with the principles expressed in the declaration of Helsinki. The participants signed an informed consent and agreed to the use of their blood in a hemolysis study. Briefly, whole blood was drawn and transferred into tubes (BD Vacutainer EDTA anticoagulant). Blood was diluted in PBS $(15 \mu \mathrm{L}: 1000 \mu \mathrm{L})$. RBC dilution $(1 \mathrm{~mL})$ was mixed with $0-100 \mu \mathrm{g} \mathrm{mL}^{-1}$ of GO samples. After $3 \mathrm{~h}$ of incubation at room temperature, RBCs were centrifuged (2000 $\times g$ for $10 \mathrm{~min}$ ) and hemolysis was analyzed by absorbance at $540 \mathrm{~nm}$ using a spectrophotometer (Thermo Scientific Multiskan GO spectrophotometer). RBCs diluted in water were used as the positive control.

2.8.2. In vitro cytotoxicity in HepG2 cells. The cytotoxic effect of the GO samples on the HepG2 cell line was evaluated by the method described in ref. 14. Cells were seeded (in DMEM supplemented with $10 \%$ FBS) in 48 -well plates at a density of 1 $\times 10^{4}$ cells per well and incubated for $24 \mathrm{~h}$. The medium was replaced with fresh serum-free DMEM and GO samples (GO, GO-A, or GO-AL) were added with concentrations from 0-100 $\mu \mathrm{g}$ $\mathrm{mL}^{-1}$ for $24 \mathrm{~h}$. Cytotoxicity was determined using a 3-(4,5dimethylthiazol-2-yl)-2,5-diphenyltetrazolium bromide (MTT)based assay and the $50 \%$ inhibitory concentration $\left(\mathrm{IC}_{50}\right)$ values were calculated.

\subsection{Cellular uptake evaluation and specificity of recognition}

To evaluate the cellular uptake, GO-A and GO-AL were labeled with fluorescein and studied on ASGPR-positive hepatoma cells HepG2 as well as ASGPR-negative HeLa cells. Cells were seeded in 48-well plates at a density of 10000 cells $/ 200 \mu \mathrm{L}$ per well using DMEM containing $10 \%$ FBS. After incubation $\left(5 \% \mathrm{CO}_{2}\right.$ at $37{ }^{\circ} \mathrm{C}$ for $24 \mathrm{~h}$ ), the cells were washed against sterile saline solution (SSS) three times, and subsequently were incubated with PBS, GO-A, or GO-AL at $10 \mu \mathrm{g} \mathrm{mL} \mathrm{m}^{-1}$ at $37^{\circ} \mathrm{C}$ for $30 \mathrm{~min}$. The cells were rinsed two times with SSS $(200 \mu \mathrm{L}$ per well). Finally, the cells were observed by confocal microscopy (Nikon Ti Eclipse C2+) with $488 \mathrm{~nm}$ lasers at $\times 20$ magnification. At the same time, as a competitive assay, the cells were simultaneously incubated with GO samples and free lactose, while for the biorecognition inhibition assay, the cells were previously incubated with lactose $(10 \mu \mathrm{g} / 100 \mathrm{~mL}$ of DMEM) and the GO samples $\left(10 \mu \mathrm{g} \mathrm{mL}{ }^{-1}\right)$ were added 30 min later.

\subsection{Statistical analysis}

The experiments were performed in triplicate and evaluated by analysis of variance (ANOVA). Also, the data results from the ELLA were analyzed by the application of the Tukey-Kramer test with $p \leq 0.05$ using NCSS 2007 (Statistical Analysis and Graphics, Kaysville, UT, USA).

\section{Results and discussion}

\subsection{Functionalization of GO with lactose}

The successful synthesis of GO sheets, APTES coating, and subsequent glycation with lactose were analyzed by Raman spectroscopy (Fig. 1). Characteristic Raman absorption bands for carbon $\mathrm{sp}^{2}$ forms (C-C bond stretch) were observed at $1608 \mathrm{~cm}^{-1}$ for GO and at $1590 \mathrm{~cm}^{-1}$ for GO-A and GO-AL, respectively. These Raman shifts are known as the $\mathrm{G}$ band. ${ }^{\mathbf{1 5}}$ The band associated with $\mathrm{sp}^{3}$ forms is the $\mathrm{D}$ band, and in GO this is attributed to the reduction in the size of the $\mathrm{sp}^{2}$ domains

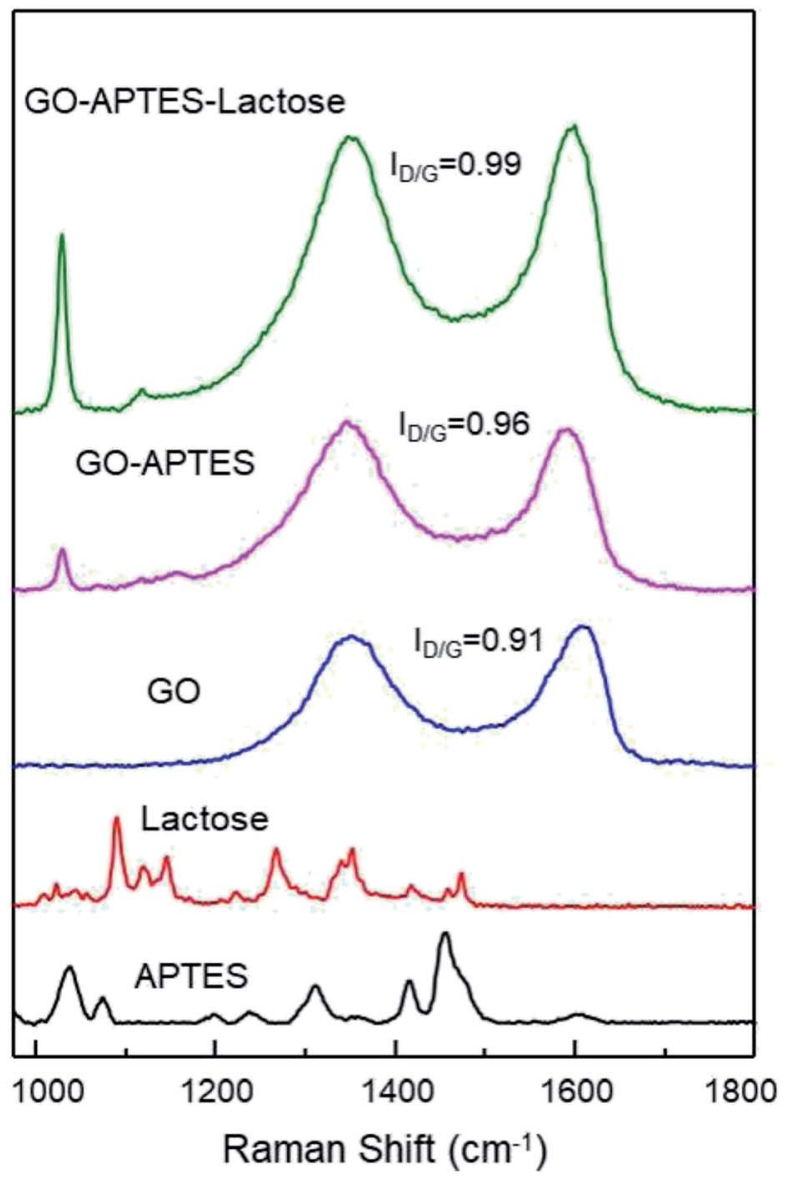

Fig. 1 Raman spectra of APTES, lactose, GO, GO-APTES, and GOAPTES-lactose. 
by the creation of defects, vacancies, and distortions during the oxidation of graphite. ${ }^{\mathbf{1 5 , 1 6}}$ All the GO sample spectra showed the $\mathrm{D}$ band at $1350 \mathrm{~cm}^{-1}$. The intensity of this band is indicative of the presence of an $\mathrm{sp}^{3}$ form, which confirmed the grafting of oxygen-containing functional groups to the graphitic plans. ${ }^{16}$ The ratio $\mathrm{D} / \mathrm{G}\left(I_{\mathrm{D} / \mathrm{G}}\right)$ showed a dependent increase with the degree of modification of GO. Fig. 1 illustrates the $I_{\mathrm{D} / \mathrm{G}}$ for GO$\mathrm{AL}, \mathrm{GO}-\mathrm{A}$, and GO $(0.99,0.96$, and 0.91 , respectively). This behavior has been reported and reveals an increase in the amount of $\mathrm{sp}^{3}$ hybridized carbon atoms due to disordered domains and defect structures of graphene induced by the covalent bonding with APTES. ${ }^{17}$ The GO-AL Raman spectra exhibited bands that also could be observed in the APTES spectrum and lactose spectrum at $1028 \mathrm{~cm}^{-1}$ (Si-OH stretching vibration) and $1118 \mathrm{~cm}^{-1}$, respectively. The above results suggest the successful lactosylation of GO.

Additionally, chemical modifications of GO were analyzed by FTIR spectroscopy. The FTIR spectra of the GO, GO-A, and GO$\mathrm{AL}$ are shown in Fig. 2. The presence of a new band was observed as a significant change in the spectrum of the modified GO (GO-A and GO-AL) at $901 \mathrm{~cm}^{-1}$, corresponding to $\mathrm{Si}-\mathrm{O}$ and amino groups, attributed to the APTES conjugation..$^{18}$ The characteristic infrared bands of carbohydrates are localized between 900 and $1199 \mathrm{~cm}^{-1} ;^{19}$ nevertheless, these were shifted and referred to the SiO-X region. ${ }^{18}$ We observed slight differences in this region for both GO-A and GO-AL, which made it difficult to identify the lactose groups. However, due to the conjugation of GO, the band observed at $1730 \mathrm{~cm}^{-1}(\mathrm{C}-\mathrm{O}$ stretching peak for carboxylic acid) vanished, but it was also evident that there was an intensification of the band at about $1600 \mathrm{~cm}^{-1}$.

Similar behavior was described by Cao et al. ${ }^{20}$ who previously described the presence of a new prominent band at $1639 \mathrm{~cm}^{-1}$ corresponding to the stretching mode of amide groups by the conjugation of GO with lactosylated chitosan. Also, Sarkar et al. ${ }^{21}$ reported the occurrence of a new absorption band at $1630 \mathrm{~cm}^{-1}$ due to the modification of GO with aminated molecules. Finally, the GO-A and GO-AL spectra showed a shift at $2092 \mathrm{~cm}^{-1}$ corresponding to the primary amine group. The

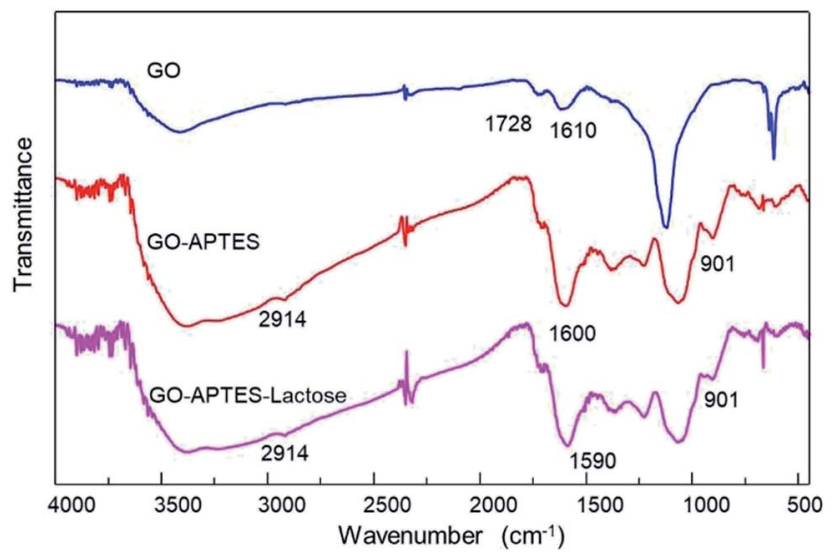

Fig. 2 ATR-FTIR spectra of GO, GO-APTES (GO-A), and GO-APTESlactose $(\mathrm{GO}-\mathrm{AL})$. above results confirm the modification with APTES and suggests the presence of lactose in GO-AL.

\subsection{Ricinus communis-lactose recognition}

Due to the ability of lectins to bind or specifically recognize carbohydrate residues, these plant proteins are considered as an excellent tool to characterize simple or complex carbohydrates present in different kinds of glycoconjugates. The lactosylation of GO was carried out first by the reaction with an aminated compound (APTES), which aided the reaction as a bridge for the subsequent glycation with lactose. The glycation reaction occurred by the formation of a Schiff base between the aldehyde group of the reducing sugar (such as glucose) and the primary amino group of a macromolecule. We modified GO with APTES and then exposed it to lactose to obtain GO-APTESlactose (GO-AL). The reaction was verified using RCA lectin, which recognizes galactoses. GO-AL samples were consistently recognized by RCA (Fig. 3), which indicated the presence of lactose in the GO sheets subjected to glycation. It also confirmed the correct closed ring structure of galactose, which is a requirement for the interaction with carbohydrate receptors. $^{22}$

\subsection{Zeta potential}

The colloidal stabilities of the GO, GO-A, and GO-AL were determined by measuring the zeta potential. The colloidal dispersion is stable when a force causes the mutual repulsion of the particles. ${ }^{23}$ In general, a particle suspension with a zeta potential of around $-30 \mathrm{mV}$ is considered as a stable dispersion. ${ }^{24}$ Table 1 shows the zeta potential values of the GO samples. The zeta potential values for all the GO samples were above $-40 \mathrm{mV}$ when dispersed in water. The zeta potential

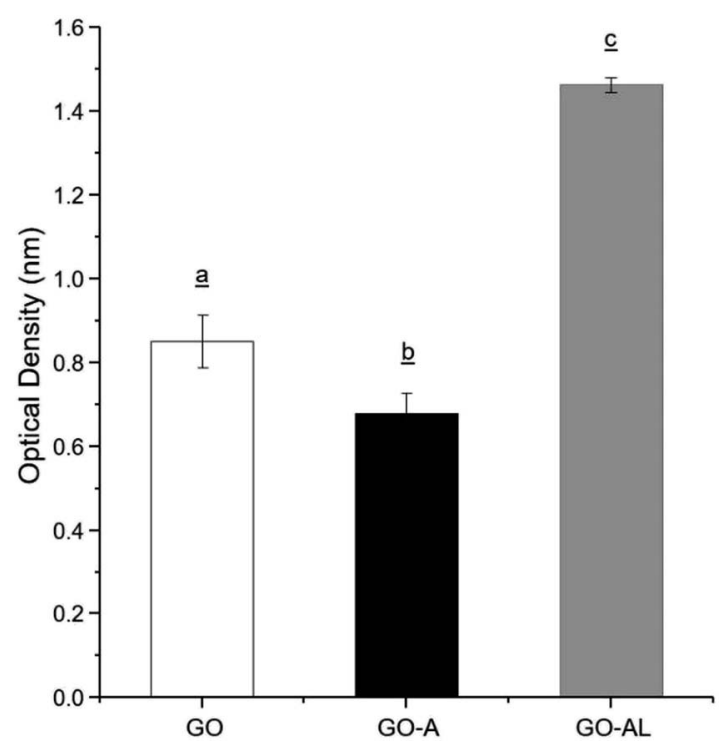

Fig. 3 ELLA for the recognition of GO, GO-A, and GO-AL by Ricinus communis lectin. Experiments were performed in triplicate and analysis was by ANOVA followed by Tukey's test; $p \leq 0.05$. Different letter $(a, b$, and $c$ ) shows statistical significance. 
Table 1 Zeta potential values $(\mathrm{mV})$ with different dispersant systems for GO, GO-A, and GO-AL ${ }^{a}$

\begin{tabular}{llll}
\hline & GO & GO-A & GO-AL \\
\hline Water & $-42.6 \pm 3.06$ & $-45.3 \pm 6.86$ & $-43.3 \pm 5.33$ \\
SS & $-16.2 \pm 9.54$ & $-25.8 \pm 11.60$ & $-20.5 \pm 3.46$ \\
PBS & $-22.2 \pm 9.27$ & $-19.9 \pm 8.38$ & $-19.6 \pm 11.10$ \\
DMEM & $-16.9 \pm 2.93$ & $-14.9 \pm 1.27$ & $-14.7 \pm 1.53$
\end{tabular}

${ }^{a}$ Zeta potential values are shown as the mean \pm standard deviation. Abbreviations: GO, graphene oxide; GO-A, graphene oxide-APTES; GO$\mathrm{AL}$, lactosylated graphene oxide; SS, saline solution; PBS, phosphate buffer saline; RPMI, Roswell Park Memorial Institute medium.

values decreased to around $-20 \mathrm{mV}$ when the GO samples were dispersed in physiological saline solution or PBS. Furthermore, a minor negative charge of around $-15 \mathrm{mV}$ was observed in the culture medium (DMEM). The moderate zeta potential $(-20$ $\mathrm{mV}$ ) of the GO samples in an electrolytic solution (saline solution or PBS) can be explained by the characteristic screening effect. The low zeta potential in DMEM can be attributed to the complex content of the molecules of this culture medium (aminoacids, vitamins, glucose, and salts) that can interact with the surface of the GO sheets, decreasing its superficial charge.

\subsection{Morphological characterization of GO and lactosylated GO}

The GO and lactosylated GO samples were observed by SEM and AFM (Fig. 4). SEM images (Fig. 4A and B) show a sheet structure of graphite as a single or stack of several layers with a variety of sizes. Also, it is possible to observe a laminar appearance for the GO-AL, while the GO is shown as corrugated sheet structures. The AFM images show the morphology and the height profiles of GO and the functionalized GO. Dispersed structures with some aggregation can be observed for both GO and functionalized GO (Fig. 4C and D). Analysis of the height profiles from the dispersed GO structures revealed a thickness of $2.396 \pm 1.29 \mathrm{~nm}$ for GO and $2.72 \pm 2.51 \mathrm{~nm}$ for GOL (Fig. 4E and F), which is consistent with previous reports for GO composites. ${ }^{16}$

\subsection{Hemolytic properties of GO}

Red blood cells (RBCs) are the most abundant cells in blood; likewise, these cells are in continuous contact with exogenous compounds that reach the circulatory system. The application of nanoparticles as therapeutic agents should consider that these will have an interaction with components in blood, mainly the RBCs. In this context, we evaluated the hemolytic effect of GO samples. Fig. 5 shows that none of the GO samples presented any hemolytic effect, even over $100 \mu \mathrm{g} \mathrm{mL}{ }^{-1}$. In Fig. 5A, we can see the viability graph of RBCs treated with GO, GO-A, and GO-AL. Also, the photographs of centrifuged RBCs incubated with GO samples shows the RBCs at the bottom and the supernatant without evidence of the red color representing free hemoglobin (Fig. 5B). It is important to mention that when increasing the GO concentration, the sheets tended to aggregate induced by the neutralization of charges with the ions dissolved
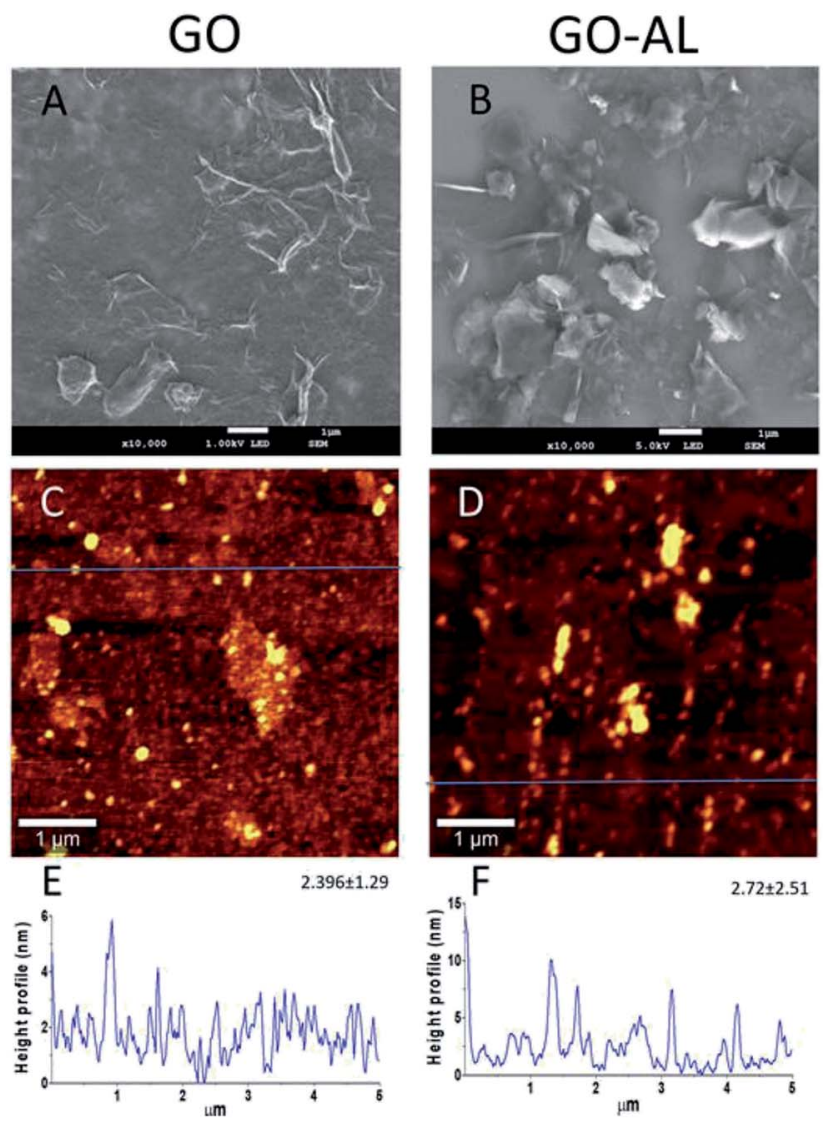

Fig. 4 Morphology and profile height of $\mathrm{GO}$ and the functionalized GO. ( $A$ and $B$ ) SEM image; ( $C$ and $D$ ) representative AFM image of GO morphology; ( $E$ and $F$ ) representative height profile from dispersed structures of $\mathrm{GO}$, extracted from the blue line. The mean of the height and the standard deviation is also presented $(N=3)$.

in PBS. ${ }^{25}$ The above can lead to a false negative of the hemolytic properties; however, in our results, even at a low concentration of GO samples $\left(0.25-50 \mu \mathrm{g} \mathrm{mL}^{-1}\right)$, no hemolysis was observed.

\subsection{In vitro cytotoxicity in HepG2 cells}

For a detailed evaluation of the cytotoxicity degree and the effects induced by the interaction of GO with hepatic cells, the MTT assay was performed. This test is based on measuring the cell viability, which is determined by the ability of mitochondria to reduce MTT. Here, the MTT results for GO samples showed no effects on the mitochondrial activity of HepG2 cells, indicating that the cells were unaffected by either nanomaterial at $0.25-100 \mu \mathrm{g} \mathrm{mL}{ }^{-1}$ (Fig. 6). These results agreed with those reported by Yuan et al. ${ }^{26}$ who reported that the GO samples do not show cellular toxicity below $100 \mu \mathrm{g} \mathrm{mL} \mathrm{m}^{-1}$. However, our cytotoxicity results contrast with the one reported by Wang et al. ${ }^{27}$ whose results indicated that GO is cytotoxic, even at low concentrations $\left(50-100 \mu \mathrm{g} \mathrm{mL}^{-1}\right)$.

The cytotoxicity can be attributed to several factors, such as the chemical composition, size, surface, dimensional characteristics, use of reducing agents for functionalization of graphene, functional groups, charges, coatings, structural defects 
A
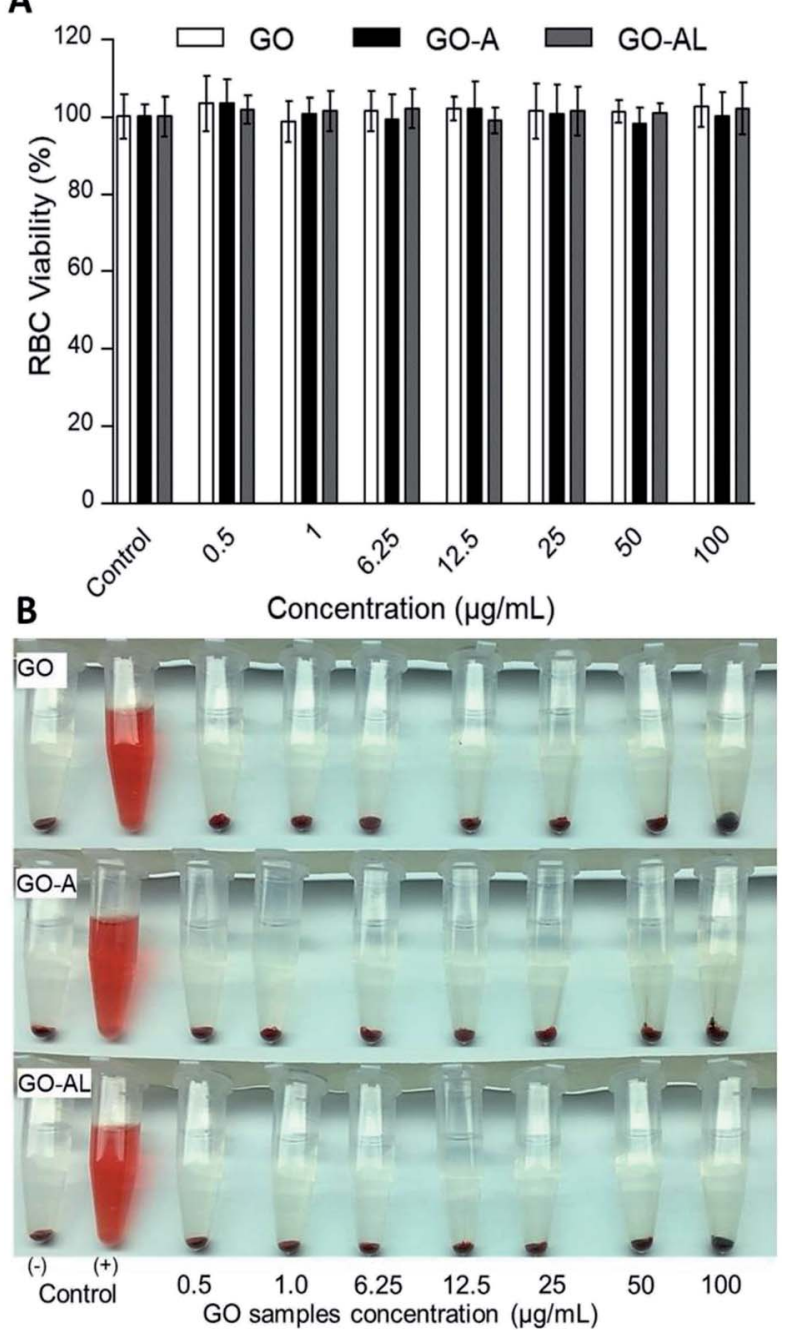

Fig. 5 Red blood cell (RBC) viability assay. RBCs were incubated with different concentration $\left(0.5\right.$ to $\left.100 \mu \mathrm{g} \mathrm{mL}^{-1}\right)$ of $\mathrm{GO}, \mathrm{GO}-\mathrm{A}$, or GO-AL. (A) Graphic representation of RBC viability was determined based on the degree of hemolysis. Data are the mean \pm standard deviation for three separate experiments. (B) Photographs of RBCs treated with GO samples. PBS and DI water served as the negative (-) and positive $(+)$ controls, respectively. The experiments were repeated in triplicate.

of graphene, and the dissolving media. ${ }^{28}$ Principally, the changes in the processes for obtaining GO can lead to a variation in the type and number of functional groups (ester, hydroxyl, and epoxide groups) and therefore, the cytotoxicity can show a discrepancy. Although none of our GO samples were cytotoxic at the concentration used $\left(0.25-100 \mu \mathrm{g} \mathrm{mL} \mathrm{m}^{-1}\right)$, it is relevant to indicate that the functionalization of the GO with lactose can increase its biocompatibility, as has been reported for graphene and other carbon-based materials. ${ }^{29}$

\subsection{Cellular interaction evaluation and specificity of recognition}

The cellular uptake interaction of FITC-labeled GO samples were studied on two different cells: ASGPR-positive cells (hepatoma

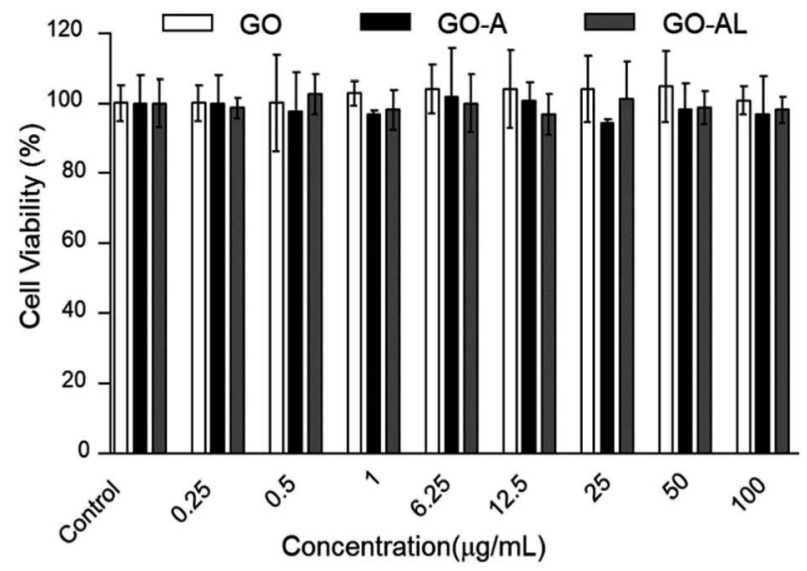

Fig. 6 MTT cytotoxicity of GO, GO-A or GO-AL at different concentration $\left(0.25\right.$ to $\left.100 \mu \mathrm{g} \mathrm{mL}^{-1}\right)$. Data are means \pm standard deviation for three separate experiments.

cells HepG2) and ASGPR-negative cells (human cervical carcinoma cells HeLa), via confocal microscopy. Fig. 7 shows a strong green fluorescence intensity with HepG2 cells exposed to GO-AL and a null fluorescence for the HeLa cells. Likewise, it can be observed that GO-A was not visualized in HepG2 cells, indicating that the modification of $\mathrm{GO}$ with lactose significantly induced the cell uptake by ASGPR-positive cells. This behavior was previously reported by Lee et al. ${ }^{14}$ They suggested that the presence of lactose on the nanoparticle surface plays a crucial role in allowing internalization by hepatocytes. Bareford and Swaan ${ }^{30}$ explained that targeting the receptor-ligand pathway offers several advantages, including the ability to exploit upregulated membrane receptors in specific diseased tissues, to control the intracellular fate for localization to acidic endosomes, and to allow for the regulated release of therapeutics from the bioresponsive vehicle. Thus, it is essential to show that the internalization is specific and mediated by the receptor-ligand.

To determine the ability of lectins to bind specific glycoconjugates, studies of the interaction inhibition are habitually carried out using a simple, specific carbohydrate as an inhibitor. ${ }^{31}$ In this regard, we evaluate the uptake of the lactosylated GO by HepG2 cells using free lactose as the competitive or inhibitor ligand. For the competitive assay, HepG2 cells were simultaneously incubated with GO-AL and free lactose. The inhibition assay was carried out by the pre-incubation of HepG2 cells with free lactose followed by GO-AL addition. Competitive tests (Fig. 7) showed that the fluorescence intensity of HepG2 cells treated with GO-AL + free lactose was decreased significantly compared to that of HepG2-GO-AL interactions.

Furthermore, the pre-incubation of HepG2 cells with free lactose seemed to induce saturation of the ASGPRs, which were unable to interact with the galactose exposed on GO-AL (Fig. 7). These results confirmed the selectivity of the asialoglycoprotein receptor toward the structures present in the lactosylated GO. Quan et al..$^{32}$ reported similar results with ASGPR positive cells and lactosylated mesoporous silica nanoparticles. They observed that the cellular internalization of lactosylated nanoparticles by HepG2 and SMMC7721 cells decreased in the 


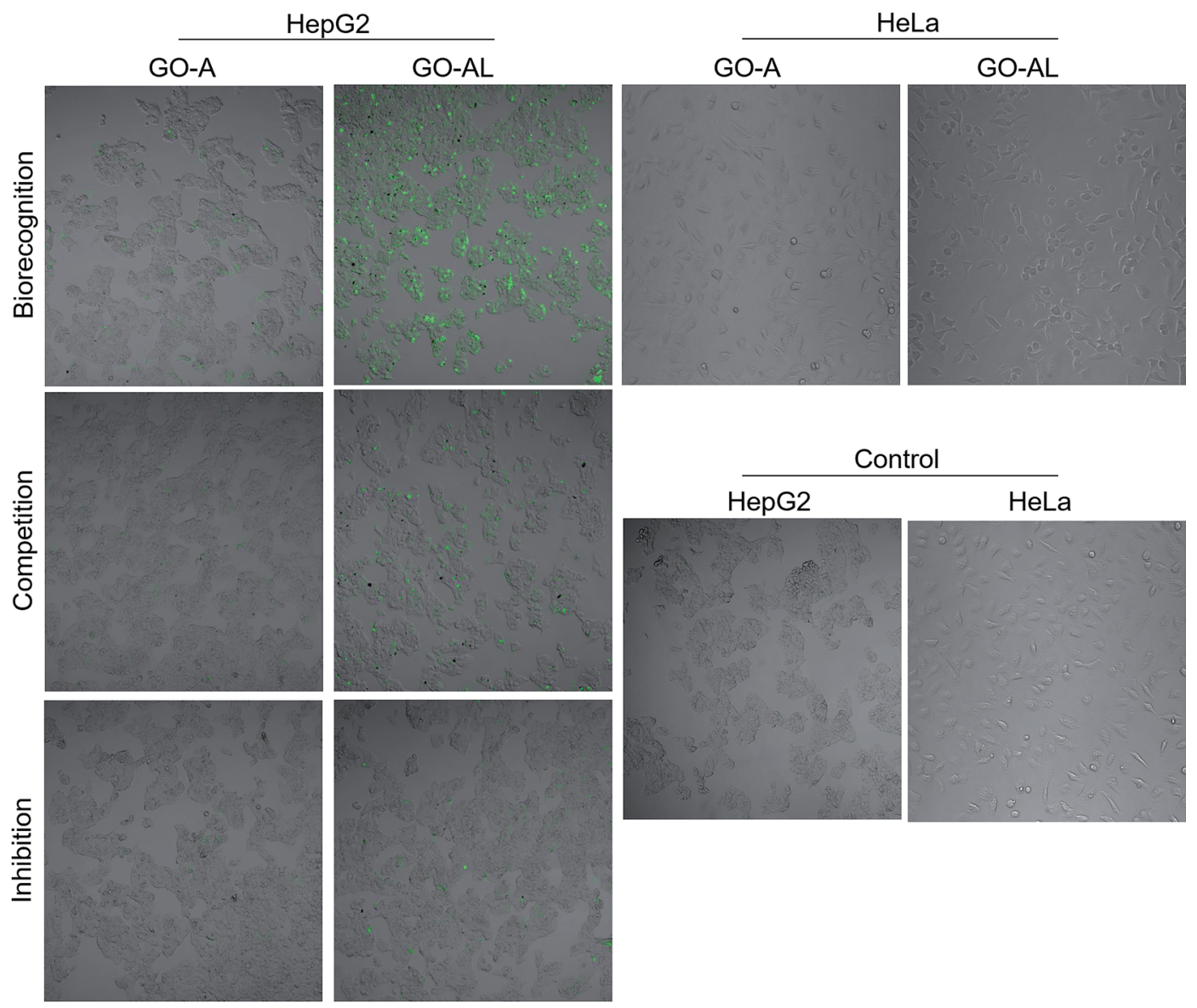

Fig. 7 Cellular interaction evaluation and specificity of recognition. HepG2 cells were incubated with GO-A and GO-AL to evaluate the receptor-ligand interaction between ASGPRs (from HepG2 cells) and galactose (from GO-AL). HeLa cells were used as negative control. To determine specific recognition competitive and inhibition assay were performed. In competition, assay cells were simultaneously incubated with GO samples and free lactose. In inhibition, the cells were first incubated with lactose and later GO-AL was added.

presence of excess free lactose. Therefore, we demonstrated the potential use of lactosylated GO as a targeted drug delivery system.

\section{Conclusions}

We presented a protocol for the conjugation of GO with lactose to obtain a glycocomposite, which did not show hemolytic and cytotoxic effects. The correct functionalization of the GO was evidenced by biorecognition with the RCA lectin and also, it allowed for specific interaction with the ASGPRs from liver cells. These results represent a promising selective drug delivery vehicle to the hepatic tissue.

\section{Conflicts of interest}

There are no conflicts to declare.

\section{Acknowledgements}

We are grateful to the CONACYT and SEP of Mexico for financial support, under projects PDPCPN-2014-248982, and PRODEP/ DSA/103.5/16/10231.

\section{Notes and references}

1 K.-H. Liao, Y.-S. Lin, C. W. Macosko and C. L. Haynes, ACS Appl. Mater. Interfaces, 2011, 3, 2607-2615.

2 C. Cha, S. R. Shin, N. Annabi, M. R. Dokmeci and A. Khademhosseini, ACS Nano, 2013, 7, 2891-2897.

3 W. S. Hummers Jr and R. E. Offeman, J. Am. Chem. Soc., 1958, 80, 1339.

4 X. Sun, Z. Liu, K. Welsher, J. T. Robinson, A. Goodwin, S. Zaric and H. Dai, Nano Res., 2008, 1, 203-212.

5 T. Zhou, X. Zhou and D. Xing, Biomaterials, 2014, 35, 41854194.

6 Y. Li, G. Huang, J. Diakur and L. I. Wiebe, Curr. Drug Delivery, 2008, 5, 299-302.

7 D. D. Mcabee, X. Jiang and K. B. Walsh, Biochem. J., 2000, 348, 113-117.

8 A. A. D'souza and P. V. Devarajan, J. Controlled Release, 2015, 203, 126-139.

9 S. Pranatharthiharan, M. D. Patel, V. C. Malshe, V. Pujari, A. Gorakshakar, M. Madkaikar, K. Ghosh and P. V. Devarajan, Drug Delivery, 2017, 24, 20-29.

10 D. Roggenbuck, M. G. Mytilinaiou, S. V. Lapin, D. Reinhold and K. Conrad, Autoimmun. Highlights, 2012, 3, 119-125. 
11 Y. Kaneo, T. Tanaka, T. Nakano and Y. Yamaguchi, J. Controlled Release, 2001, 70, 365-373.

12 T. Tanaka, S. Hamano, Y. Fujishima and Y. Kaneo, Biol. Pharm. Bull., 2005, 28, 560-562.

13 C. Managit, S. Kawakami, M. Nishikawa, F. Yamashita and M. Hashida, Int. J. Pharm., 2003, 266, 77-84.

14 C. Lee, B. Kim, S. Lee, T. H. Kim, J. O. Kim, E. S. Lee, K. T. Oh, H.-G. Choi, S. D. Yoo and Y. S. Youn, Colloids Surf., B, 2017, 152, 183-191.

15 K. Krishnamoorthy, M. Veerapandian, R. Mohan and S.-J. Kim, Appl. Phys. A: Mater. Sci. Process., 2012, 106, 501506.

16 S. Perumbilavil, P. Sankar, T. Priya Rose and R. Philip, Appl. Phys. Lett., 2015, 107, 051104.

17 L. Hu, P. Jiang, P. Zhang, G. Bian, S. Sheng, M. Huang, Y. Bao and J. Xia, J. Mater. Sci., 2016, 51, 8296-8309.

18 R. M. Pasternack, S. Rivillon Amy and Y. J. Chabal, Langmuir, 2008, 24, 12963-12971.

19 A. Gallegos-Tabanico, J. A. Sarabia-Sainz, H. M. SarabiaSainz, R. C. Torres, A. M. Guzman-Partida, G. R.-C. Monfort, E. Silva-Campa, A. J. Burgara-Estrella, A. Angulo-Molina and M. Acosta-Elias, Acta Biochim. Pol., 2017, 64, 671-677.

20 X. Cao, S. Zheng, S. Zhang, Y. Wang, X. Yang, H. Duan, Y. Huang and Y. Chen, J. Nanosci. Nanotechnol., 2015, 15, 2052-2059.
21 K. Sarkar, G. Madras and K. Chatterjee, $R S C A d v .$, 2015, 5, 50196-50211.

22 A. I. Ledesma-Osuna, G. Ramos-Clamont and L. VázquezMoreno, Acta Biochim. Pol., 2008, 55, 491-497.

23 S. Kashyap, S. Mishra and S. K. Behera, J. Nanopart., 2014, 2014, 1-6.

24 F. Baskoro, C.-B. Wong, S. R. Kumar, C.-W. Chang, C.-H. Chen, D. W. Chen and S. J. Lue, J. Membr. Sci., 2018, 554, 253-263.

25 Y. Wang, B. Zhang and G. Zhai, RSC Adv., 2016, 6, 6832268334.

26 X. Yuan, Z. Liu, Z. Guo, Y. Ji, M. Jin and X. Wang, Nanoscale Res. Lett., 2014, 9, 108.

27 A. Wang, K. Pu, B. Dong, Y. Liu, L. Zhang, Z. Zhang, W. Duan and Y. Zhu, J. Appl. Toxicol., 2013, 33, 1156-1164.

28 S. Gurunathan and J.-H. Kim, Int. J. Nanomed., 2016, 11, 1927.

29 Y. Chen, A. Star and S. Vidal, Chem. Soc. Rev., 2013, 42, 45324542.

30 L. M. Bareford and P. W. Swaan, Adv. Drug Delivery Rev., 2007, 59, 748-758.

31 S. André, H. Kaltner, K. Kayser, P. V. Murphy and H.-J. Gabius, Histochem. Cell Biol., 2016, 145, 185-199.

32 G. Quan, X. Pan, Z. Wang, Q. Wu, G. Li, L. Dian, B. Chen and C. Wu, J. Nanobiotechnol., 2015, 13, 7. 